\title{
Histoarchitectural Changes in the Liver Following Lactational Lead Intoxication in Sprague Dawley Rats
}

\author{
Ayodeji. S. Odukoya ${ }^{1, *}$, Israel. O. Akinfolarin², Abimbola. O. Odukoya ${ }^{3}$ \\ ${ }^{1}$ Department of Anatomy and Cell Biology, Faculty of Basic Medical Sciences, \\ Obafemi Awolowo University (OAU), Nigeria. \\ ${ }^{2}$ Department of Anatomy, Faculty of Basic Medical Sciences, College of Health Sciences, Bowen \\ University, Iwo, Osun State, Nigeria.
${ }^{3}$ School of Nursing, Obafemi Awolowo University Teaching Hospital Complex (OAUTH), Ile Ife, Osun-State, Nigeria. \\ ${ }^{*}$ Correspondence: ODUKOYA, Samson O Ayodeji, PhD
}

Correspondence address: Department of Anatomy and Cell Biology, OAU

Email address: goshevnigeria@yahoo.com; Tel: +2348036153842; +2348076959940

Keywords: Liver, Histopathological, Histological, Lead, Pb, Lactational, Intoxication.

\begin{abstract}
The present experiment was designed to study the histoarchitectural changes in the liver following lactational lead $(\mathrm{Pb})$ intoxication in rats.

A total of 12 adult female and 4 male rats were used in the experiment and 32 offspring for the analysis of lactational lead intoxication. The offspring were divided into four groups. Groups B, C and $\mathrm{D}$ were administered $10 \mathrm{mg} / \mathrm{dL}, 30 \mathrm{mg} / \mathrm{dL}$ and $70 \mathrm{mg} / \mathrm{dL}$ of lead acetate respectively, via drinking water for 21 days through the lactating mothers while group A was control. The livers of the pups were observed using histological methods. One-way ANOVA was used to analyze data, followed by Tukey post hoc test for multiple comparisons.

The results from the analysis showed that the total body weight, body length and liver weights were only slightly altered in the $\mathrm{Pb}$ intoxicated groups. Using relative liver weights alone revealed some form of hepatomegaly among the experimental groups. The results revealed a dose-dependent increase in blood lead concentration. Histopathological evidences revealed moderate to severe histoarchitectural distortions along $\mathrm{Pb}$ concentration gradient.

Lactational lead intoxication portends dose dependent histopathological changes in the liver of SD rats.
\end{abstract}

\section{Introduction}

Lead $(\mathrm{Pb})$ poisoning is one of the oldest known workplace and environmental hazards. A modern understanding of the small amount of $\mathrm{Pb}$ essential to cause harm did not come about until the latter half of the 20th century. No safe threshold for $\mathrm{Pb}$ exposure has been discovered; thus, there is no known sufficiently small amount of $\mathrm{Pb}$ that will not cause harm to the body $[1,2]$.

Lead has been detected in the breast milk of women in population-based studies; however, the availability of high-quality data to assess the risk for toxicity to the breastfeeding infant is limited $[2,3]$. Lead, as well as cadmium and mercury have been categorized as developmental and reproductive toxicants [4]. Even though infant blood lead levels have been correlated with the duration of breastfeeding [5], the ratio of breast milk lead levels to blood lead levels has been found to be less than 3\% [6]. Conferring to the American Academy of Pediatrics, because of the contribution of $\mathrm{Pb}$ levels found in infant formula and other infant foods, breastfed infants of mothers with normal blood lead levels are actually exposed to slightly less $\mathrm{Pb}$ than if they were not breastfed [7].

According to a research conducted by Bashir and Noory [8]; adult males of the Wistar albino rats (Rattus norvegicus) were exposed to lead acetate trihydrate in drinking water $(0.0 \%, 0.25 \%$, $0.5 \%, 1 \%$ and $2 \%$ for $1-12$ months) to investigate histological and histochemical alterations induced by lead intoxication in the liver. Chronic exposure to subtoxic concentrations of lead produced portal 
triads' mild chronic inflammation, Kupffer cells hyperplasia and occasional fatty change, seen together with hemosiderosis [8]. Exposure also increased the activities of alkaline phosphatase and $\alpha$-glycerophosphate-dehydrogenase which might be an adaptation to the metabolic, structural and functional changes in the organelles of hepatic cells due to lead intoxication [8]. These findings revealed that chronic exposure to lead produced significant histological and histochemical changes in the liver of the Wistar albino rats [8]. According to another publication by Corpas et al. [9], the effects of $\mathrm{Pb}$ intoxication during pregnancy and lactation were studied in the hepatic system of pups and young Wistar rats to test the hypothesis that gestational and lactational lead exposure alters the normal function of the liver in neonates. In contrast, Can et al. [10] concluded that higher blood lead levels are not related to toxicity in battery and muffler repair workers. Total protein, globulin, cholesterol, LDH, and ALP levels were within normal levels, however, they were slightly higher than the control levels. Increased LDH among the workers seems to be related rather to other causes than to the liver injury. This present study investigated the effect of lactational lead intoxication on the histological signatures of the liver in offspring Sprague Dawley (SD) rats.

\section{Materials and Methods}

A total of 12 female and 4 male SD rats (chosen mainly for its calmness and ease of handling), assessed and presumably healthy, were given unlimited access to standard rat feed and distilled water were kept under standard laboratory conditions at a constant natural light/dark cycle to acclimatize for 1 week. The sexually matured female SD rats were mated at a proportion of 3 females to 1 male.

After parturition, mothers and their pups were randomly divided into 4 equal groups of 8 pups each: 1 control group (A) and 3 treatment groups $(\mathrm{B}, \mathrm{C}$ and $\mathrm{D}$ respectively) that received 10,30, and $70 \mathrm{mg} / \mathrm{dL}$ of lead acetate in their drinking water dam from parturition, day 1 to weaning, day 21 of the lactational period, patterned after previous studies; $\mathrm{B}=10 \mathrm{mg} / \mathrm{dL} ;[11] ; \mathrm{C}=30 \mathrm{mg} / \mathrm{dL}$ [9]; and $\mathrm{D}=70 \mathrm{mg} / \mathrm{dL}[12]$.

\section{Lead Acetate (Dosage and Preparation)}

$200 \mathrm{mg}, 600 \mathrm{mg}$, and $14000 \mathrm{mg}$ of Lead acetate powder were weighed with a Mettler Toledo high sensitivity weighing balance and prepared in $2000 \mathrm{ml}$ of distilled water each, giving a final solution of $10 \mathrm{mg} / \mathrm{dL}, 30 \mathrm{mg} / \mathrm{dL}$ and $70 \mathrm{mg} / \mathrm{dL}$ respectively. The solutions were administered to the lactating mothers through their water dams ad libitum.

\section{Euthanasia of Animals}

The animals were sedated using a chloroform-damped cotton wool in a vacuum (air-tight chamber), the crown-rump length was measured in $\mathrm{cm}$ using a calibrated tape ruler, then weighed on a weighing balance, and figures recorded. Thoraco-abdominal incision was made, and blood was collected through cardiac puncture using a 2-ml needle into heparinized bottles. The animal was then perfused with phosphate buffered saline to clear blood from the organs before the organs were harvested. The liver was excised, blotted dry on filter paper, weighed on Mettler Toledo weighing balance and fixed by immersion in 10\% formal saline (dispensed in correctly labeled specimen bottles) for further histological processing. Blood samples from each group were collected in heparinized bottles (male and female apart). Collected blood samples were centrifuged; the plasma was then decanted from the blood into another sample bottle and kept in the freezer at $-4^{0} \mathrm{C}$ till use.

\section{Estimation of Blood Lead Levels (BLL)}

$1 \mathrm{ml}$ of whole blood was mixed with $3 \mathrm{ml}$ of $2 \mathrm{M}$ conc $\mathrm{H} 2 \mathrm{SO} 4$ to lyse the red blood cells to release the $\mathrm{Pb}$ within the cells. Mixture was then centrifuged at $4000 \mathrm{rpm}$ for $15 \mathrm{~min}$. Supernatant was decanted into a plain specimen bottle and centrifugation repeated to ensure clear supernatant. Each sample was then analyzed using the atomic absorption spectrometer (AAS) set at standard wavelength $(283.3 \mathrm{~nm})$ for lead analysis. Five standard lead analysis solutions $(0,2.5,5,10$ \& $20 \mathrm{ppm}$ ) were run through the AAS followed by each sample, and the blood Pd concentration was recorded by the AAS. 


\section{Histological techniques}

The fixed liver tissue was processed for paraffin wax embedding method 48 hours post fixation. $5 \mu \mathrm{m}$ thick sections were cut from the paraffin embedded tissues with a Rotary microtome and stained with hematoxylin and eosin stain to demonstrate the general histoarchitecture of the liver according to the method of Avwioro (2002) [13].

\section{Histochemical techniques}

Periodic Acid Schiff stain (PAS) staining was done according to the method of Avwioro (2002) [13] using the $5 \mu$ liver tissue sections.

\section{Photomicrography}

Stained sections were viewed under a Leica DM750 microscope (Leica Microsystems, Heerbrugg, Switzerland) with digital camera attached (Leica ICC50) and digital photomicrographs were taken at various magnifications.

\section{Statistical analysis}

One-way ANOVA was used to analyze data using SPSS 23 (SPSS Inc., Chicago, Illinois, USA), followed by Tukey test for multiple comparisons. Statistically significant difference was set at $\mathrm{p}<0.05$.

\section{Results}

From the results of the Total Body Weight (TBW) of the male rats, the following were observed in comparison with the control group: There were significant decreases in the TBW of Group B $(10 \mathrm{mg} / \mathrm{dL})$ and Group $\mathrm{C}(30 \mathrm{mg} / \mathrm{dL})$ as shown in Table 1 . The increase in the TBW of Group D $(70 \mathrm{mg} / \mathrm{dL})$ was not statistically significant at $\mathrm{p}>0.05$.

In the results of the Total Body Length (TBL) of male rats, the following were observed in comparison with the control group: In general, the changes in the TBL are generally insignificant at $p>0.05$. The statistically significant increase in the TBL observed in Group $B(10 \mathrm{mg} / \mathrm{dL})$ is inconsequential compared with other groups (Table 1).

Considering the results of the Liver Weight (LW) and Relative Liver Weight (RLW) of male rats, the following were observed in comparison with the control group: There were significant decreases in the LW of Group B $(10 \mathrm{mg} / \mathrm{dL})$ and Group C $(30 \mathrm{mg} / \mathrm{dL})$. There was also a significant increase in the LW of Group D $(70 \mathrm{mg} / \mathrm{dL})$ at $\mathrm{p}<0.05$, (Table 1). Using the mean relative liver weight (RLW) calculated as mean organ weight divided by the mean total body weight, there appeared to be liver weight increase across experimental groups compared to the Control, except in group C. Relative weight is highest in group D that received the highest dose.

Table 1: Showing the Results of Analysis TBW, TBL and LW of Male Sprague-Dawley.

\begin{tabular}{lcccc}
\hline & & 21 DAYS & & \\
& TBW $(\mathrm{g})$ & TBL $(\mathrm{cm})$ & LW $(\mathrm{mg})$ & RLW \\
CONTROL & $29.00 \pm 2.309$ & $18.50 \pm 0.866$ & $1309.30 \pm 61.904$ & 0.045 \\
& & & & \\
GROUP B & $19.75 \pm 0.750^{*}$ & $25.00 \pm 2.000^{*}$ & $971.50 \pm 136.50^{*}$ & 0.049 \\
$\begin{array}{l}(10 \mathrm{mg} / \mathrm{dL}) \\
\text { GROUP C }\end{array}$ & $22.50 \pm 0.500^{*}$ & $16.55 \pm 1.450$ & $856.00 \pm 34.00^{*}$ & 0.038 \\
$\begin{array}{l}(30 \mathrm{mg} / \mathrm{dL}) \\
\text { GROUP D }\end{array}$ & $34.33 \pm 1.202$ & $19.83 \pm 0.600$ & $1821.30 \pm 36.168^{*}$ & 0.053 \\
\hline$(70 \mathrm{mg} / \mathrm{dL})$ & & & & \\
\hline
\end{tabular}

Values are expressed as the mean \pm standard error of the mean. ${ }^{*}$-Statistically significant difference from the control group@ $@<<0.05$, TBW- Total Body Weight, TBL- Total Body Length, LW- Liver weight, and RLW - Relative Liver Weight, $\mathrm{n}=8$. 
The results of the Total Body Weight (TBW) of female rats, the following were observed in comparison with the control group: There were significant decreases in the TBW across all treated groups (B, C and D) when compared to the control (Table 2).

The Total Body Length (TBL), in comparison with the control group showed statistically significant increases in Group B $(10 \mathrm{mg} / \mathrm{dL})$ and Group D $(70 \mathrm{mg} / \mathrm{dL})$, while an insignificant decrease was observed in Group C (30mg/dL) at $\mathrm{p}>0.05$ (Table 2).

The results of Liver Weight (LW), the following were observed in comparison with the control group: The decreases observed in groups B (10mg/dL), Group C (30mg/dL) and Group D (70mg/dL) were not statistically significant at $\mathrm{p}>0.05$, (Table 2 ). Using the mean relative liver weight, the group $\mathrm{D}$ that received the highest dose of the Lead Acetate water seem to exhibit extreme hepatomegaly in comparison to the other groups.

Table 2: Showing the Results of Analysis TBW, TBL and LW of Female Sprague-Dawley.

\begin{tabular}{lllll}
\hline & 21 DAYS & & & \\
& TBW $(\mathrm{g})$ & TBL $(\mathrm{cm})$ & LW $(\mathrm{mg})$ & RLW \\
CONTROL & $26.50 \pm 0.500$ & $17.25 \pm 0.250$ & $1302.00 \pm 4.000$ & 0.049 \\
$\begin{array}{l}\text { GROUP B } \\
\begin{array}{l}(10 \mathrm{mg} / \mathrm{dL}) \\
\text { GROUP C } \\
(30 \mathrm{mg} / \mathrm{dL})\end{array}\end{array}$ & $21.33 \pm 1.333^{*}$ & $16.83 \pm 1.013$ & $842.00 \pm 71.668$ & 0.039 \\
$\begin{array}{l}\text { GROUP D } \\
(70 \mathrm{mg} / \mathrm{dL})\end{array}$ & $20.50 \pm 0.500^{*}$ & $20.50 \pm 0.500^{*}$ & $1292.00 \pm 124.304$ & 0.063 \\
\hline
\end{tabular}

Values are expressed as the mean \pm standard error of the mean.* -Significantly different from the control group @ $\mathrm{p}<$ 0.05, TBW- Total Body Weight, TBL- Total Body Length, LW- Liver weight, and RLW - Relative Liver Weight, $\mathrm{n}=8$.

The blood $\mathrm{Pb}$ concentration from the AAS recorded showed a dose dependent concentration gradient according to the exposure each group was subjected to. Unexpectedly, the control group without $\mathrm{Pb}$ administration also revealed some level of blood lead, showing the ubiquitous nature of $\mathrm{Pb} ; \mathrm{A}=0.819 \mu \mathrm{g} / \mathrm{dL} ; \mathrm{B}=10.968 \mu \mathrm{g} / \mathrm{dL} ; \mathrm{C}=15.652 \mu \mathrm{g} / \mathrm{dL}$ and, $\mathrm{D}=21.228 \mu \mathrm{g} / \mathrm{dL}$ (Fig. 1).

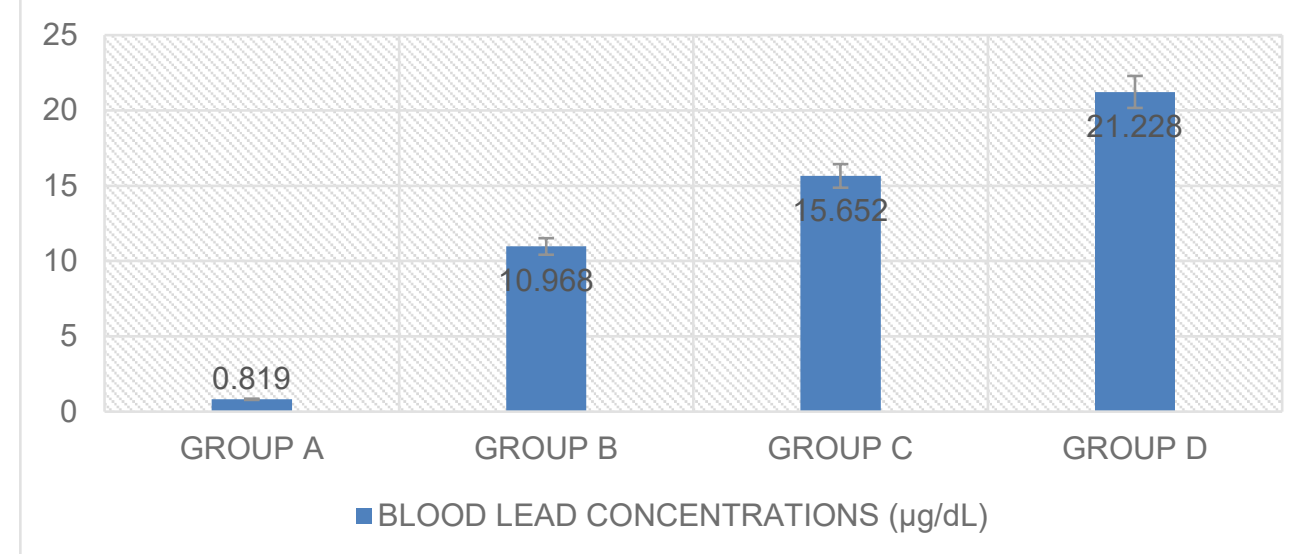

Figure 1: Bar Chart Showing the Blood Lead Concentration $(\mu \mathrm{g} / \mathrm{dL})$ in SD rats across the groups.

\section{Histological and Histopathological Results}

Histopathological findings revealed normal liver histoarchitecture in the Control group A (Figure 2A). Portal Triads (PT) consisting of Portal arterioles (PA; a branch of Hepatic artery), Portal venule (PV; of Hepatic portal vein) and Bile duct (BD) are well outlined. The Central Veins (CV) shows congestions in groups $\mathrm{B}, \mathrm{C}$ and $\mathrm{D}$. Hepatocytes $\mathrm{H}$ are arranged in cords or plates of 
Hepatocytes, Sinusoids S, which are clear and well outlined in group A show congestions (SC) in the intoxicated groups, especially C and D (Fig. 2A-D). Prominent Nucleoli (pN) and multinucleated hepatocytes $(\mathrm{Hm})$; signs of actively dividing mitotic cells are observed across the groups. Disarrayed hepatocytes $(\mathrm{Hd})$, nuclear vacuolation $(\mathrm{nV})$, Necrotic tissue $(\mathrm{Nt})$, tissue vacuolation $(\mathrm{tV})$ due to fatty degeneration, neutrophilic invasion (Ni) are identified in groups B, C and D. Groups $\mathrm{C}$ and D showed vivid signs of tissue haemorrhage $(\mathrm{tH})$ as shown in figures 3A-D. The PAS staining of the glycogen contents of the liver tissue of the control group A shows a not so vivid differential staining compared to the treated groups B $(10 \mathrm{mg} / \mathrm{dL}), C(30 \mathrm{mg} / \mathrm{dL})$ and $\mathrm{D}(70 \mathrm{mg} / \mathrm{dL})$, although this result is limited by lack of diastase control for a more convincing comparison (Figure 4A-D).
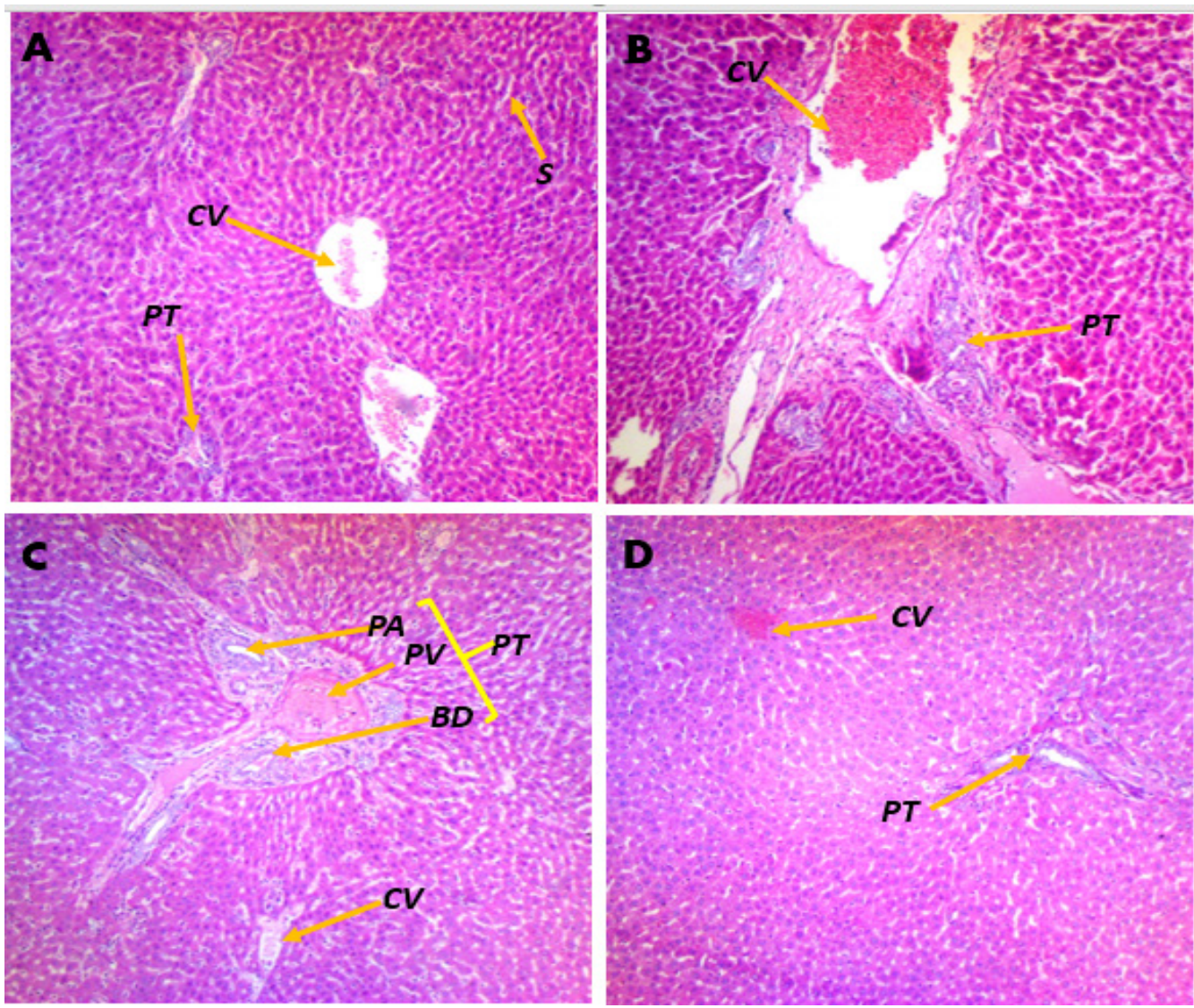

Figure 2: Showing micrographs of the control group A, and groups B $(10 \mathrm{mg} / \mathrm{dL}), \mathrm{C}(30 \mathrm{mg} / \mathrm{dL})$ and D $(70 \mathrm{mg} / \mathrm{dL})$. Portal triads $(\mathrm{Pt})$ consisting of Portal arteroles (PA; a branch of Hepatic artery), Portal venule (PV; of Hepatic portal vein) and Bile duct (BD). The Central Veins (CV) shows congestions in groups B, C and D. Hepatocytes $\mathrm{H}$ are arranged in cords or plates of Hepatocytes, Sinusoid S, showing congestions in groups $\mathrm{C}$ and D especially. (H \& E X100). 


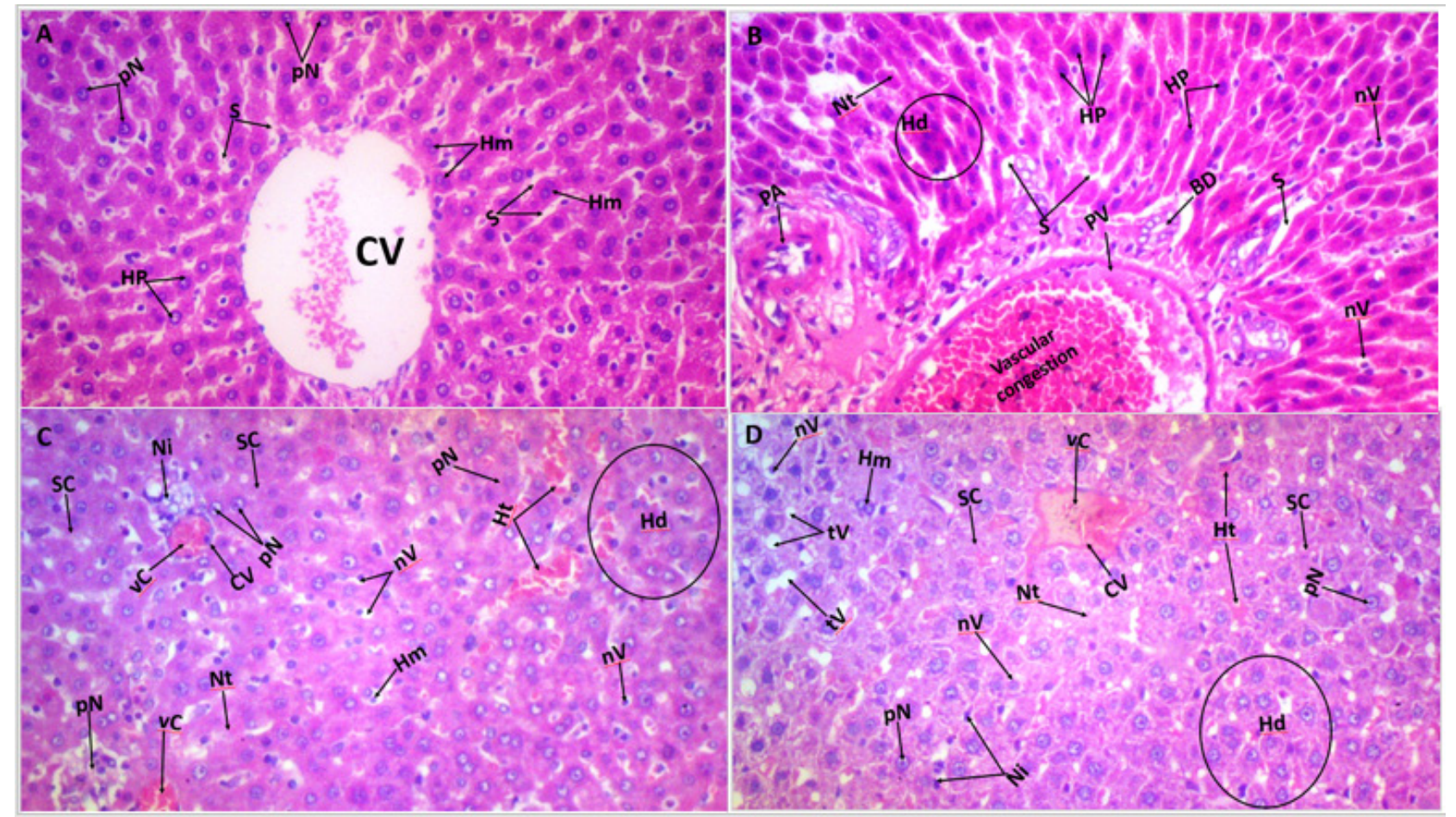

Figure 3: Shows micrographs of the control group A, and groups B (10mg/dL), C (30mg/dL) and D (70mg/dL). Portal triads (PT) consisting of Portal arteroles (PA; a branch of Hepatic artery), Portal venule (PV; of Hepatic portal vein) and Bile duct (BD). The Central Veins (CV) shows vascular congestions (vC) in groups B,C and D. Hepatocytes $(\mathrm{H})$ are arranged in cords or plates of Hepatocytes, Sinusoid S, showing congestions in groups $\mathrm{C}$ and D especially, Sinusoidal Congestion (SC). Prominent Nucleoli (pN) and multinucleated hepatocytes $(\mathrm{Hm})$ are signs of actively dividing mitotic cells. Disarrayed hepatocytes (Hd), nuclear vacuolation (nV), Necrotic tissue $(\mathrm{Nt})$, tissue vacuolation $(\mathrm{tV})$ due to fatty degeneration, neutrophilic invasion $(\mathrm{Ni})$ are identified in groups B, C and D. Groups C and D showed vivid signs of tissue haemorrhage (tH). (H \& E x400).
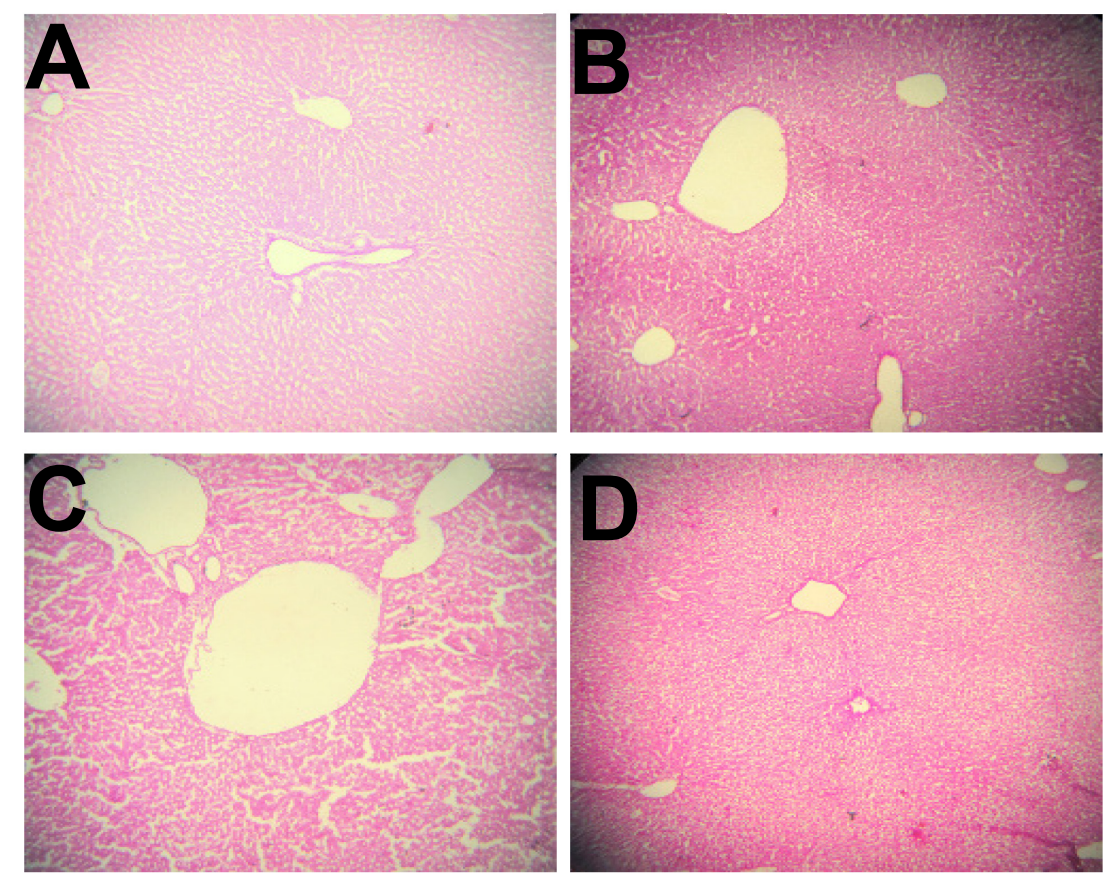

Figure 4: Shows the staining of the glycogen contents of the liver tissue of the control group A, and treated groups B (10mg/dL), C (30mg/dL) and D (70mg/dL) (PAS x100). 


\section{Discussion}

The results of the analysis of the blood lead level of the experimental animals showed a negligible lead concentration in the blood of the control group. There was a remarkable concentration of lead in the blood of the treated groups and this correlates with the results of Vinod et al., [14] in their research on occupational lead exposure and liver functions in battery manufacturing company workers around Kolhapur (Maharashtra); and those of Gato et al., [15] that assessed lead effects on Fisher-344 Rats. The concentration of lead in the blood ascended significantly across the treated groups. It was lowest in the group administered $10 \mathrm{mg} / \mathrm{dL}$ of lead and highest in that of $70 \mathrm{mg} / \mathrm{dL}$. Lead in blood is primarily in the red blood cells (99\%) rather than the plasma.

Most of the $\mathrm{Pb}$ found in red blood cells is found bound within the cell rather than the erythrocyte membrane [16]. Once absorbed in the bloodstream, $\mathrm{Pb}$ is primarily distributed among two compartments - the distribution to the soft tissues (a more rapid turnover pool) such as the liver, lungs, spleen, brain, ovaries and the kidneys, and the slower distribution to the skeleton (a slower turnover pool) $[17,18]$. During pregnancy, $\mathrm{Pb}$ is often remobilized from bone and may be transferred from mother to fetus. About 80 percent of $\mathrm{Pb}$ in fetal cord blood appears to be derived from maternal bone stores. Maternal $\mathrm{Pb}$ can also be transferred to infants during breastfeeding. The placenta and breast ensure that the developing fetus and young child are exposed early [19]. There are two implications from this result; first is that $\mathrm{Pb}$ was transmitted from maternal milk to the offspring via breastfeeding $[2,19]$, and secondly it confirms the ubiquity of $\mathrm{Pb}$ since the control group was not administered any $\mathrm{Pb}$, yet it was found in trace amount in their blood.

The highest soft tissue (liver, skeletal muscle, skin, fat, kidney, lung, aorta, and brain) concentration of $\mathrm{Pb}$ in adults occurs in the liver and renal cortex [19]. Another implication of liver being the highest soft tissue repository for $\mathrm{Pb}$ in the body may thus offer some explanations to the hepatomegaly observed in the mean relative liver weight observed in this study among the $\mathrm{Pb}$ treated groups $[17,18]$.

Previous studies indicated that $\mathrm{Pb}$ exposure may impair normal bone growth and remodeling, together with other factors resulting in stunted growth, low body weight and impaired and/or delayed physical maturity [20,21,22], these assertions may give insight into the decreased bodyweight differences observed among the $\mathrm{Pb}$ treated groups compared to the control.

Inorganic $\mathrm{Pb}$ ions are not known to be metabolized in the body but they are complexed by macromolecules [16]. In the metabolism of inorganic $\mathrm{Pb}$, it forms complexes with a variety of proteins (albumin or $\delta$-aminolevulinate dehydrogenase) and non-protein ligands (non-protein sulfhydryl) [19]. Metabolism of organic $\mathrm{Pb}$ compounds is primarily by oxidative dealkylation catalyzed by cytochrome P-450 in the liver. For example, excretion of tetraethyl Lead in the urine takes three forms; diethyl Lead, ethyl Lead, and inorganic Lead [19]. The histology of a normal liver tissue shows a solid organ composed of pink-staining hepatocytes. The portal triads lie in the parenchyma while the sinusoids radiate into the central veins. These histological features of a normal liver tissue are consistent with those observed in the histology of the control group [8,23]. The implications of these findings both affirms the fact that all experimental animals were in healthy condition prior to treatment with various concentrations of lead acetate via lactational lead intoxication.

Histological investigations of the treated groups revealed from moderate to relatively severe histopathological changes in the liver tissue of SD rats treated with different concentrations of lead acetate [8]. According to Corpas et al. [9], in their study of the alterations of the hepatic system in neonates and pups following lead intoxication of mothers during gestation and lactation, indicated that even a minute amount of lead introduced into the body system of an individual, can intoxicate the liver to elicit pathological changes in the liver tissue [1], even if mild [2].

The histological findings from the $\mathrm{H} \& \mathrm{E}$ stained tissues of group $\mathrm{C}(30 \mathrm{mg} / \mathrm{dL})$ showed more aggravated tissue damage than seen in the control and group B but not as much as the group treated with $70 \mathrm{mg} / \mathrm{dL}$ of lead. This suggests that liver pathology in lead intoxication is dose dependent, similar to results obtained by previous researchers on the histological and histochemical alterations induced by lead intoxication in the liver [24]. The histology from group D of experimental animals $(70 \mathrm{mg} / \mathrm{dL})$ showed a higher extent of tissue damage than those of the control and any other treated 
experimental group. Exposure to this high concentration of lead produced changes in the hepatocytes, portal triads and the sinusoids [8]. The differential blood lead concentration gradient observed in this experiment is also expressed in the extent of liver tissue damage across the group; the group with highest blood $\mathrm{Pb}$ concentration revealed the most damaged tissue [8,15]. Findings from previous studies established these same histopathological outcomes [8,9]. The alterations in the hepatic tissues observed by previous researchers include nuclear vesiculation, binucleation, cytoplasmic inclusions, cytoplasmic swelling, hydropic degeneration, necrosis and reduction in glycogen content $[8,9,10]$, which are consistent with our findings.

The liver plays a role in the regulation of carbohydrate homeostasis. It uses glucose as fuel and has the ability to store it as glycogen within the hepatocytes [25]. The magenta staining of the PASpositive parenchyma of the control and $\mathrm{Pb}$ treated groups by PAS stain indicates that the normal glycogen storage function of the liver was intact [8], and not adversely affected in treated groups. Lead has been observed to concentrate in the nucleus and perturb cell proliferation and DNA synthesis in vivo [26]. However, following the histology of the experimental animals in this research, a reduction in the glycogen content cannot be substantiated, although admittedly, a lack of diastase control sections might be a great limitation to our experimental outcomes. Other differences observed in results may be due to the different routes of administration of lead used and the duration of exposure. Currently, $\mathrm{Pb}$ poisoning is considered the leading environmental health threat to children [27], though Hai-Hsuan et al. still highly recommended breastfeeding, they concluded that prevention strategies including behavior modification and education on proper nutrition should be provided to women who are at high risk of toxicant exposure [28].

\section{Conclusion}

This study has been able to further establish that lactational lead intoxication has detrimental effects on the histo-architechtonics of the liver in experimental rats, in a dose dependent manner. Furthemore, lead is actively secreted into breastmilk of lead intoxicated mothers, which can be actively transferred to sucklings via breastfeeding, as such women must take necessary precautions during breastfeeding since breastfeeding is still strongly recommended.

\section{Conflict of interest}

The authors unanimously declare no conflict of interest, every necessary detail was agreed upon during the preparation of the work.

\section{References}

[1] Centers for Disease Control and Prevention (CDC) (2013). Morbidity and Mortality Weekly Report (MMWR). www.cdc.gov/mmwr Retrieved 25th April 2014

[2] Agency for Toxic Substances and Disease Registry (ATSDR) (2019). Case Studies in Environmental Medicine (CSEM): Lead Toxicity. Website at URL: http://www.atsdr.cdc.gov/csem/csem.html.

[3] PDF: https://www.atsdr.cdc.gov/csem/lead/docs/csemlead_toxicity_508.pdf. Accessed on $3^{\text {rd }}$ March, 2020.

[4] Centers for Disease Control and Prevention (CDC) (2012). www.cdc.gov Retrieved 25th April 2014.

[5] Dix-Cooper L. and Kosatsky T. (2018). Blood mercury, lead and cadmium levels and determinants of exposure among newcomer South and East Asian women of reproductive age living in Vancouver, Canada. Science of the Total Environment; 619-620:(2018) 1409-1419

[6] Lozoff B, Jimenez E, Wolf AW, Angelilli ML, Zatakia J, and Jacobson SW (2009). Higher infant blood lead levels with longer duration of breastfeeding. J Pediatr; 155:663-7. 
[7] Gulson BL, Yui LA, and Howarth D (1998). Delayed visual maturation and lead pollution. Sci Total Environ; 224: 215-9.

[8] American College of Obstetricians and Gynaecologist (ACOG) (2012). Lead screening during pregnancy and lactation. Committte Opinion. Obstet Gynecol; 120:416-20

[9] Bashir, M Jarrar; and Noory, T Taib (2012). Histological and Histochemical alterations in the liver induced by lead chronic toxicity. Saudi Journal of Biological Sciences; 19 (2): 203-210.

[10] Corpas I; Benito MJ; Marquina D; Castillo M; Lopez N; and Antonio MT (2002). Gestational and lactational lead intoxication produces alterations in the hepatic system of rat pups. Ecology \& Environmental Safety; 51 (1): 35-43.

[11] Can S, Bağcı C, Ozaslan M, Bozkurt Aİ, Cengiz B, Çakmak EA, Kocabaş R, Karadağ E, Tarakçıŏlu M (2008). Occupational lead exposure effect on liver functions and biochemical parameters. Acta Physiologica Hungarica; 95 (4), pp. 395-403 DOI: 10.1556/APhysiol.95.2008.4.6:

https://www.researchgate.net/publication/23474247_Occupational_lead_exposure_effect_on_ liver_functions_and_biochemical_parameters [accessed Mar 03 2020].

[12] Dietrich K N, Krafft K M, Bornschein R L, Hammond P B, Berger O, Succop P A. (1987). Low-level fetal lead exposure effect on neurobehavioral development in early infancy. Pediatrics 1987;80:721-30.

[13] Cory-Slechta D A (1996). Relationships between Pb- induced changes in neurotransmitter system function and behavioural toxicity. Neurotoxicology; 18:673-688.

[14] Avwioro, O. G. (2002). Histochemistry and Tissue Pathology. 1st Edition. May 2002. ISBN 978 35627-9-7. Pp 218-219

[15] Vinod R. Bhagwat, Arun J. Patil, Jyotsna A. Patil, and Ajit V. Sontakke (2008). Occupational lead exposure and liver functions in battery manufacture workers around Kolhapur (Maharashtra). Al Ameen J Med Sc I; 1 (1): 2 -9.

[16] Gato W., Eversole R., Means J. (2008). Assessing Lead Effects on Fisher-344 Rats Using ICPMS and Histology. The internet journal of toxicology; 6: 2.

[17] Tarago, O (2012). Lead toxicity. Agency for Toxic Substances and Disease Registry. Retrieved from www.atsdr.gov on 10/4/2019

[18] Patrick L (2006): Lead toxicity: A review of the literature. Part 1: Exposure, evaluation, and treatment. Altern Med Rev 2006, 11(1):2-22.

[19] Juberg, R. (2000). Lead and Human Health. Retrieved from www.acsh.org on 11/4/2019.

[20] Avalos, J. (2009). Public Health Goal for Lead in Drinking Water. California Public Health Goal; California Environmental Protection Agency; Office of Environmental Health Harzard Assessment, Pesticide and Environmental Toxicology Branch, California State, U.S.A. pp 145: Retrieved from www.oehha.ca.gov on 11/04/2019.

[21] Ronis , M.J.J. ; Aronson , J. ; Gao , G.G. ; Hogue , W. ; Skinner , R.A. ; Badger , T.M. and Lumpkin, G.K. (2001) . Skeletal Effects of Development lead exposure in Rats . Toxicological Sciences , 62:321-329.

[22] Escribano, A., M. Revilla, E. R. Hernandez, C. Seco, J. Gonzalez-Riola, L. F. Villa, H. Rico. (1997), Effect of lead on bone development and bone mass: A morphometric, densitometric, and histomorphometric study in growing rats. Calcified Tissue International. 60(2): 200-203.

[23] Gruber, H. E., H. C. Gonick, F. Khalil-Manesh, T. V. Sanchez, S. Motsinger, M. Meyer, C. F. Sharp. (1997). Osteopenia induced by long-term, low- and high-level exposure of the adult rat to lead. Mineral \& Electrolyte Metabolism. 23(2): 645-73. 
[24] Young Barbara, James S. Lowe, Alan Stevens, and John W. Heath (2006). Liver and Pancreas; in Wheather's Functional Histology, 5th edition. Elsevier Limited: Ch15; pp 274-281. ISBN 9780808923312.

[25] Gavin N. Levinthal and Anthony S. Tavill (1999). Liver Disease and Diabetes. Clinical Diabetes; 17: 2.

[26] Milosevic N, and Maier P. (2000). Lead stimulates intercellular signaling between hepatocytes and Kupffer cells. Eur J Pharmacol; 401:317-328

[27] Coogan T P, Shiraishi N, Waalkes M P (1994). Apparent quiescence of the metallothionein gene in the rat ventral prostate: Association with cadmium-induced prostate tumours in rats. Environ Health Perspect; 102: 137-139.

[28] Gillis S Bruce, Zarema Arbieva, and Igor M Garvin (2012). Analysis of lead toxicity in human cells. BMC Genomics 2012, 13:344@ @ttp://www.biomedcentral.com/1471-2164/13/344.

[29] Hai-Hsuan Chao, Chih-Hung Guo, Chung-Bin Huang, Pei-Chung Chen; Hsiu-Chuan Li, DerYun Hsiung, Yu-Kung Chou (2014). Arsenic, Cadmium, Lead, and Aluminium Concentrations in Human Milk at Early Stages of Lactation; Pediatrics and Neonatology (2014)55: 127 - 134. 